Bangladesh J. Bot. 43(3): 283-291, 2014 (December)

\title{
SELECTION PARAMETERS FOR FRUIT YIELD AND RELATED TRAITS IN CHILLI (CAPSICUM ANNUUM L.)
}

\author{
Tasso Yatung, RaKesh KR DubeY*, ViKas Singh, \\ Garima UPADHYAY AND AK PANDEY \\ Department of Vegetable Science, College of Horticulture \& Forestry, \\ CAU, Pasighat, Arunachal Pradesh, India
}

Key words: Capsicum annuum, Selection parameter, Related traits, Fruit yield

\begin{abstract}
Thirty genotypes of chilli were evaluated in RBD with three replications at vegetable research farm, CHF, CAU, Pasighat, Arunachal Pradesh, India during kharif, 2011. Variability, correlation and path analysis were carried out to study the character association and contribution, respectively. Analysis of variance revealed significant differences among the genotypes for all traits. High PCV and GCV, heritability, genetic advance were observed for days to first flowering, plant height, number of seed per fruit, number of fruit per plant, ascorbic acid and fruit yield per plant. Correlation indicated that fruit yield per plant was positively and significantly correlated with number of branch per plant, number of fruit per plant and chlorophyll content while negative and significant association was established with ascorbic acid content. Maximum positive direct effect on fruit yield per plant was imposed by fruit weight, number of fruit per plant, number of seed per fruit and capsaicin content.
\end{abstract}

\section{Introduction}

Chilli (Capsicum annuum L., Solanaceae), native the new world tropics are now widely cultivated for uses as species or vegetables in the temperate zone as well as in the tropics. It is an important constituent of many food adding. However, colour, vitamin and pungency and therefore indispensible to the United States and World food Industries (Green leaf 1986). A wide variability in chilli fruit morphology, pungency, bearing habit and crop duration is found throughout India (Asati and Yadav 2004). The production and consumption of chilli in North eastern region of India has immense potential considering its congenial agro-climatic conditions. A large number of chilli accessions are cultivated in the region but no serious attempts have been made to improve them for higher productivity and acceptability. It is, therefore essential to assess the quantum of genetic variability, nature of character association with respect to different characters, which would help breeders in planning a successful breeding programme. Although the correlation coefficient analysis is useful in determining the relative influence of the various characters on yield, it does not provide an exact picture of the relative importance of each of the characters towards the yield. Path coefficient analysis proves helpful in partitioning the correlation coefficient into direct and indirect effects. It provides realistic basis for allocation of appropriate weightage to various yield components. Therefore, 30 chilli genotypes were collected from different parts of the country and an attempt was made to study the genetic variability, interrelationships among important characters and their direct and indirect effects on fruit yield by path coefficient analysis.

*Author for correspondence: <rksdubey@gmail.com>. 


\section{Materials and Methods}

The present research was carried out in vegetable research farm, College of Horticulture and Forestry, Central Agricultural University, Pasighat, Arunachal Pradesh, India (altitude $153 \mathrm{~m}$ above mean sea level, and $28^{\circ} 04^{\circ} \mathrm{N}$ and $95^{\circ} 22^{\circ} \mathrm{E}$ ). The soil is sandy loam with $\mathrm{pH}$ 6.7. The experimental material for the present study was comprised of 30 genotypes of chilli. The experiment was laid out in RCBD with three replications. The spacing between row to row 60.0 $\mathrm{cm}$ and plant to plant $45.0 \mathrm{~cm}$ was maintained with accommodating 58 number of plant in each plot of $3.5 \times 4.5 \mathrm{~m}$. About 20 metric tonne (mt) of well decomposed cow-dung manure was mixed in the soil at field preparation. Fertilizer was applied @ $90 \mathrm{~kg} \mathrm{~N}, 60 \mathrm{~kg} \mathrm{P}_{2} \mathrm{O}_{5}$ and $60 \mathrm{~kg} \mathrm{~K} 2 \mathrm{O}$ per hectare. The standard cultural operations were adopted whenever needed. The observations were recorded on five randomly selected plants of each genotype in accordance with the descriptor list of International Plant Genetic Research Institute, Rome, Italy on plant height (cm), number of primary branch per plant, days to first flowering, fruit length $(\mathrm{cm})$, fruit diameter $(\mathrm{cm})$, number of fruit per plant, average fruit weight (g), green fruit yield per plant (g), number of seed per fruit, ascorbic acid (mg/100 g), capsaicin content (\%) and chlorophyll content (mg/g). Ascorbic acid content was determined by the method as described by Jagota and Dani (1982). Capsaicin content (\%) was determined by the method as described by Balasubramaniam et al. (1982) and chlorophyll content (mg/g) was estimated by the method as suggested by Arnon (1949) and illustrated by Witham et al. (1971). Analysis of variance was calculated according to Singh and Chaudhary (1985). Traits that differed significantly were further utilized for estimation of the genetic parameters. The phenotypic and genotypic coefficient of variability and heritability (bs) was calculated as per formula given by Burton and de Vane (1953). The expected genetic advance resulted from selection of 5 per cent superior individuals were worked out as suggested by Johnson et al. (1955). Genotypic and phenotypic correlation coefficients were estimated according to the formulae given by Al-Jibouri et al. (1958). The direct and indirect effects were calculated by solving the following set of simultaneous equations proposed by Dewey and Lu (1959).

\section{Results and Discussion}

Analysis of variance indicated significant differences among genotypes for all the traits (Table 1). Sufficient genetic variability for many traits had also been reported by Smitha and Basavaraj (2006). The genotype CHFC-16 was earliest in first flowering (33.93 days). The genotype CHFC27 took the longest time to first flowering (61.27 days). Green fruit yield per plant varied between 73.02 and $531.38 \mathrm{~g}$. The genotype CHFC-26 had higher fruit yield (531.38 g). Genotype CHFC-27 had the highest capsaicin content (2.07\%). However, minimum value was recorded in CHFC-3 (0.24\%). High ascorbic acid content was found in genotype CHFC-15 (370.33 mg/100 g). However, minimum value was recorded in CHFC-2 (135 mg/100 g). The maximum chlorophyll content was observed in genotype CHFC-13 $(0.77 \mathrm{mg} / \mathrm{g})$. However, minimum value was recorded in CHFC-11 (0.16 mg/g) (Table 2). Phenotypic and genotypic variances were highest 14424.88 and 11928.77, respectively for green fruit yield per plant and lowest 0.02 and 0.02 , respectively for chlorophyll content (Table 3). The highest estimates of phenotypic (PCV) and genotypic (GCV) coefficient of variation were observed for capsaicin content (72.19, 71.63\%). However, the lowest estimates of PCV and GCV were recorded in plant height (18.81, 15.76\%). High heritability estimates was recorded for all the characters which ranged between 68.47 and $98.44 \%$. These results were in agreement with Chattopadhyay et al. (2011). Genetic advance was high for capsaicin content (146.39\%). However, low value was observed for plant height (27.22\%). This was in conformity with Datta and Jana (2010). From the above study on mean performance and

other genetic parameters of different characters, it was revealed that the characters viz., number of 


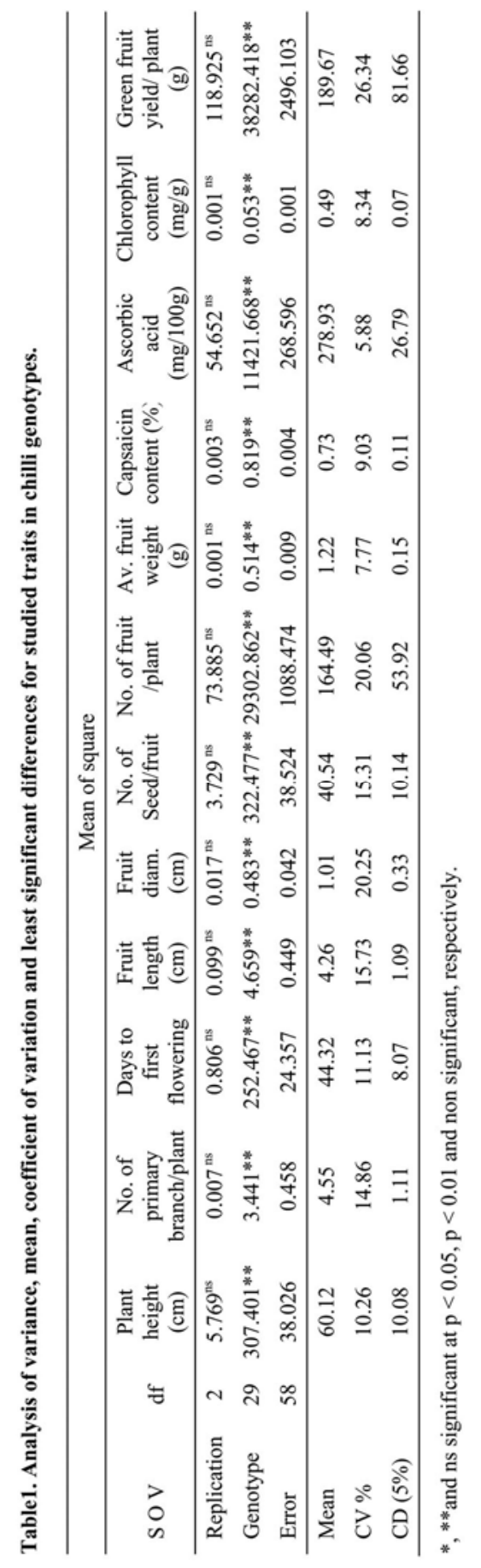




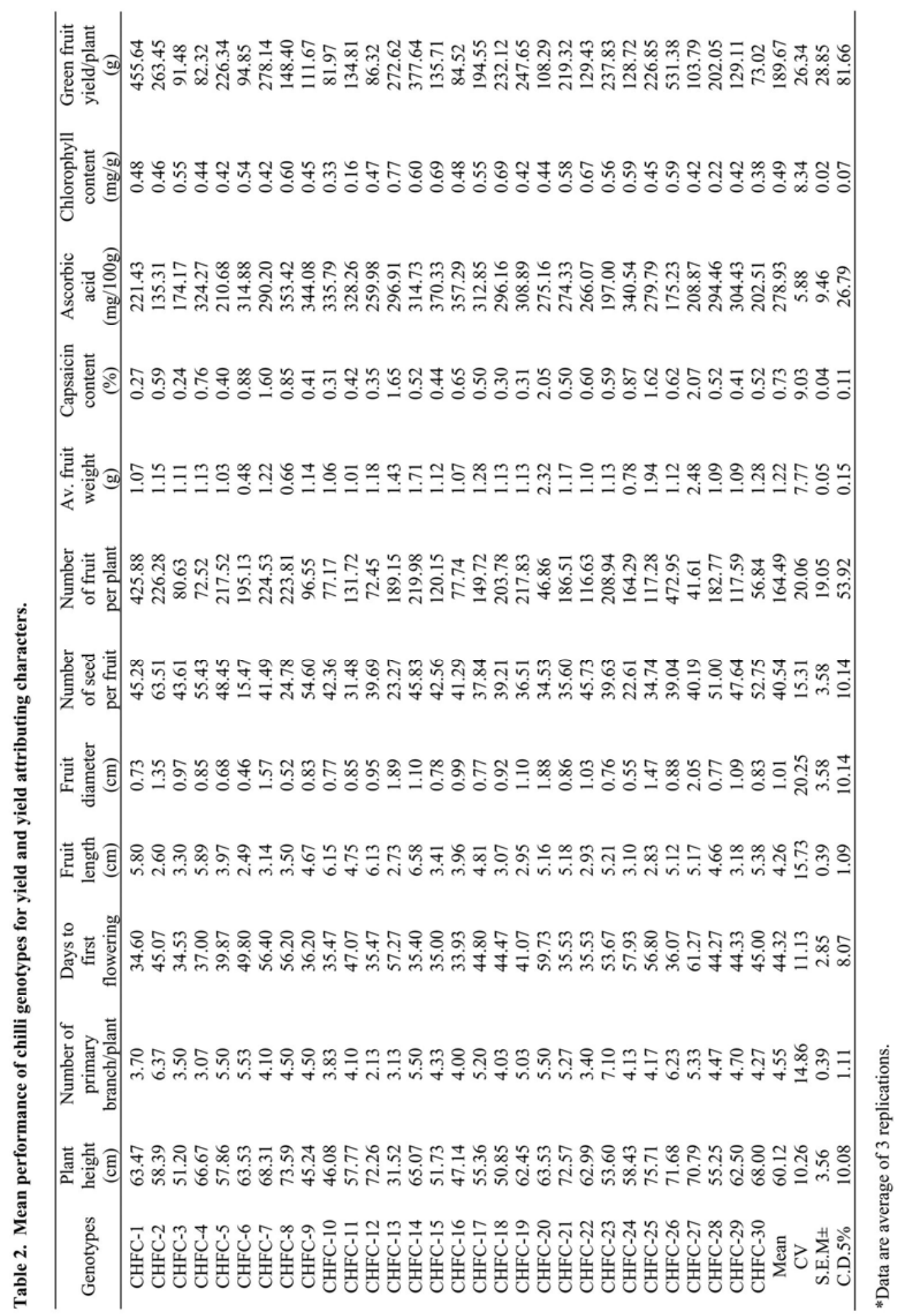




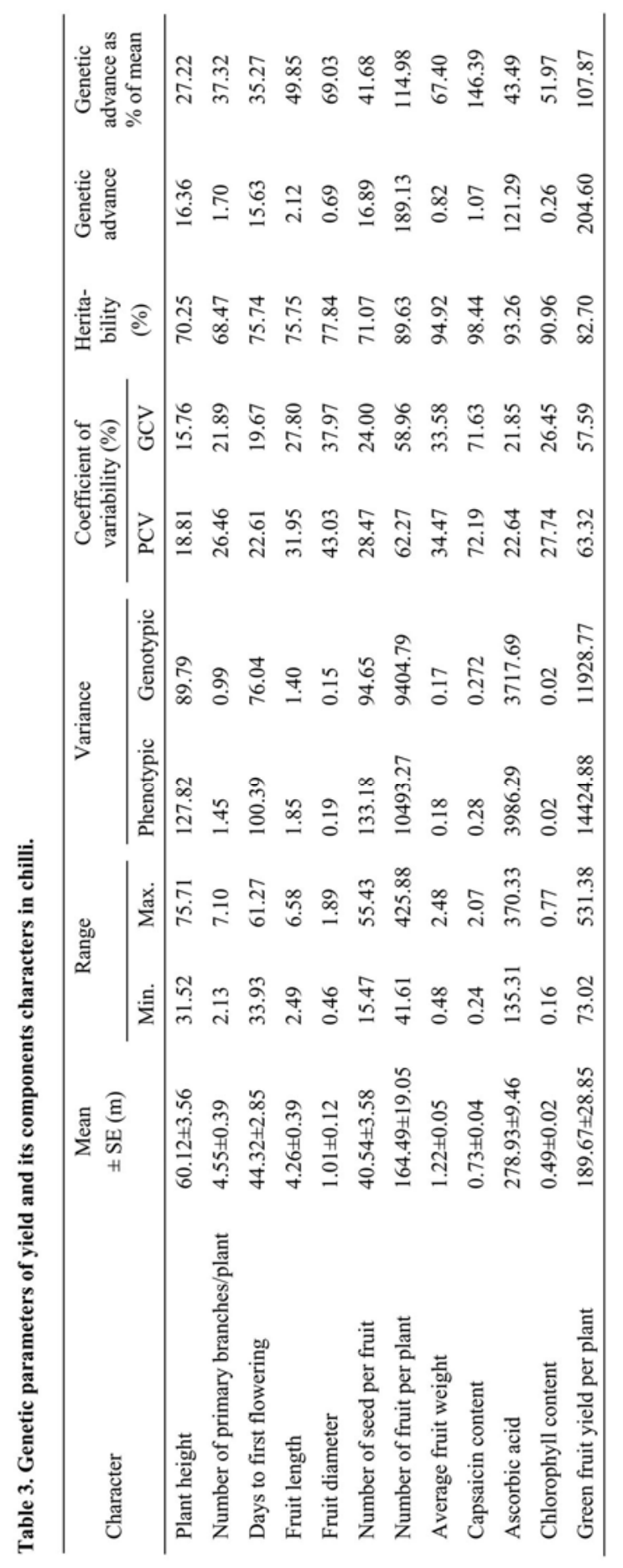




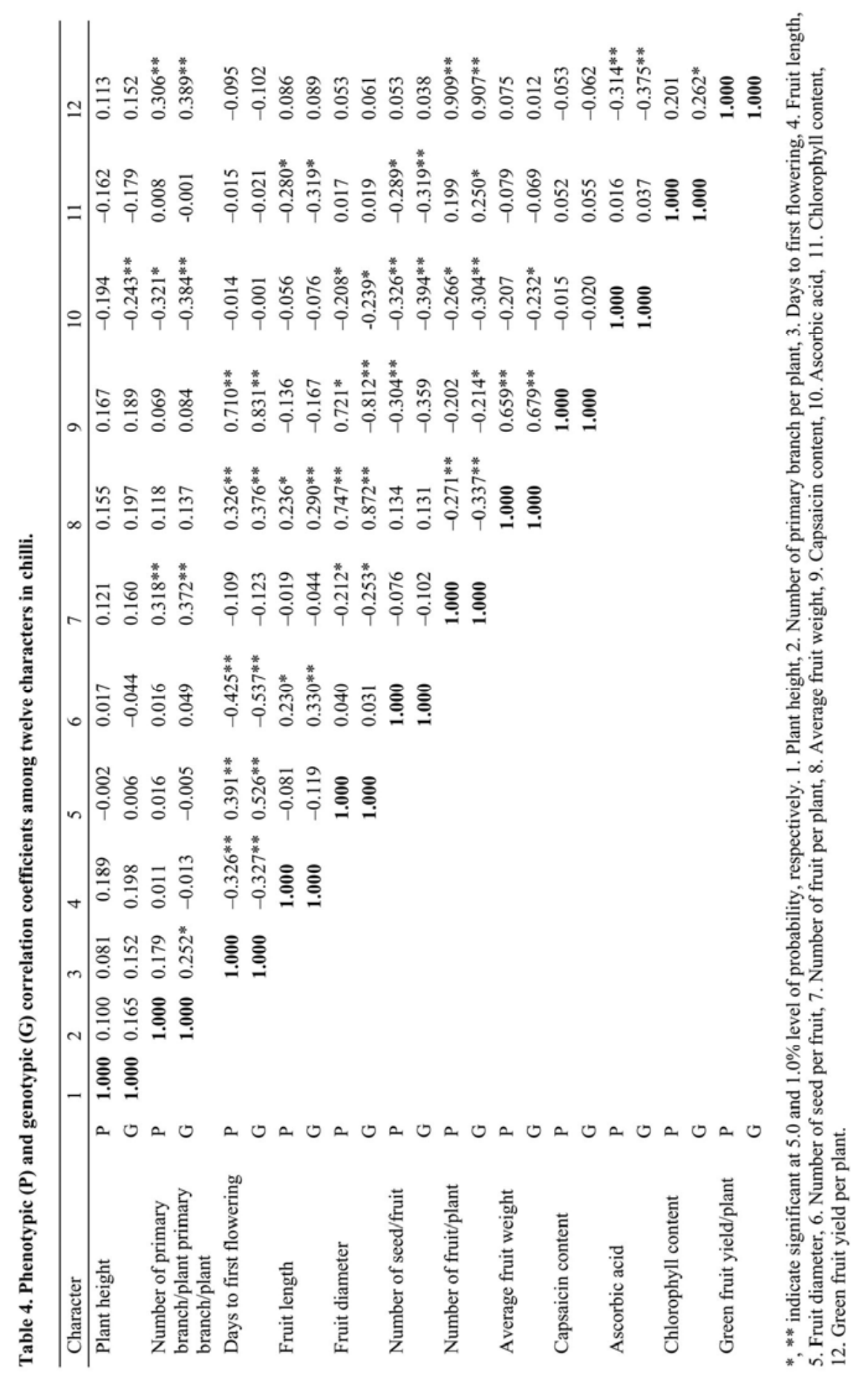




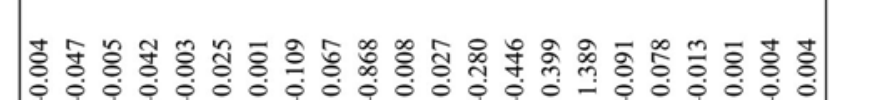

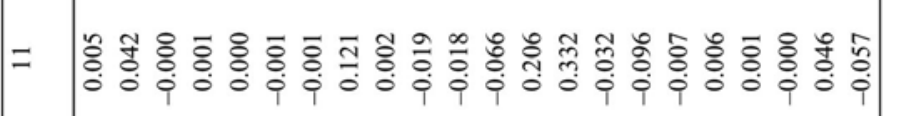

으

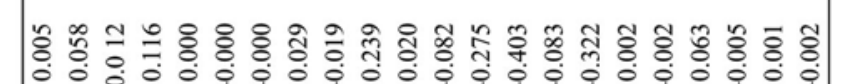

善

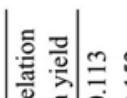

ठ্ল

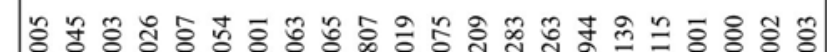

许

i

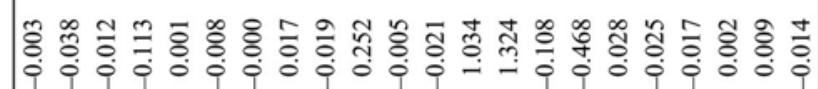

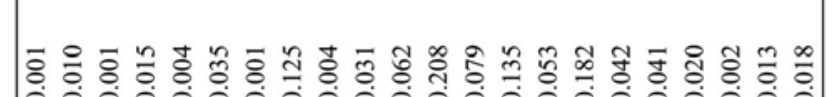

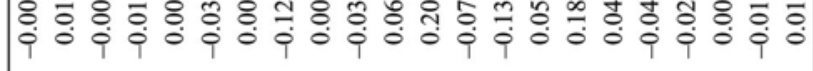

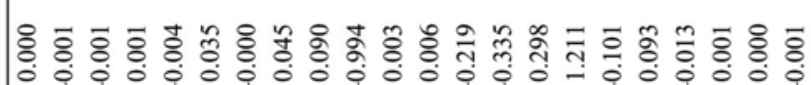

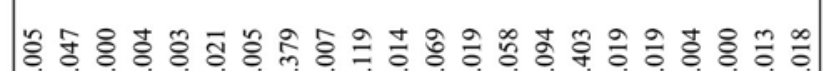

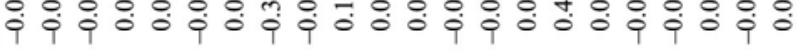

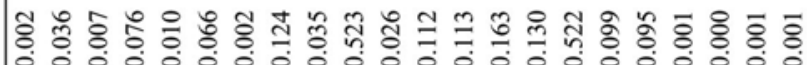

i

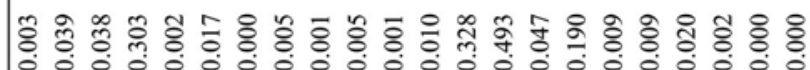

离

诺

สิ่

귱

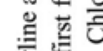

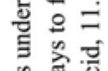

空:

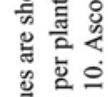


fruit per plant, fruit length, fruit diameter and fruit weight were the most important traits for improving the genotypes for higher fruit yield and may be applied for selection in chilli. In general, genotypic correlation was higher than phenotypic correlation, indicated low influence due to environment and the expression of characters being mainly due to genetic factors (Table 4). Correlation studies revealed that characters like number of primary branch per plant, number of fruit per plant and chlorophyll content had significant positive correlation with fruit yield per plant both at genotypic and phenotypic level. Similar result was also reported by Datta and Jana (2010) in their experiment. Chlorophyll content had positive and significant correlation with fruit yield per plant. This result was corresponding with the observation of Mathew et al. (2004). However, negative and significant association of green fruit yield per plant was illustrious with ascorbic acid content both at genotypic and phenotypic level, indicated that green fruit yield and ascorbic acid content could not be improved simultaneously through selection and it is strongly suggested that this character should not be emphasized for direct selection of high yielding genotype. Path coefficient analysis is one such method which partition correlation into direct and indirect effects. In the present investigation, green fruit yield per plant was taken as dependent variable and other 11 traits were considered as causal variables (Table 5). Fruit weight had maximum positive direct effect on fruit yield per plant and indicated that this was the real independent characters and has maximum contribution towards increase in fruit yield per plant. These observations were in agreement with Datta and Jana (2010). Path coefficient analysis revealed that number of fruit per plant, fruit weight and number of seed per fruit were the most important traits affecting fruit yield per plant. However, relative importance of days to first flowering and capsaicin content cannot be ignored when selection is practiced for improving the green fruit yield per plant in chilli. The residual factor determines how best the causal factors account for the variability of the dependant factors, the fruit yield per plant in this case. The residual effect at genotypic level (0.221) was of moderate and negligible in magnitude. The variables studied explain about $77.9 \%$ of the variability. It indicates that some characters which have not been studied here need to be included in this analysis to account fully for the variation in fruit yield per plant. In conclusion, the correlation coefficient analysis revealed that fruit yield per plant had significantly positive genotypic correlation with number of fruit per plant, weight of fruit, length of fruit and chlorophyll content. Path analysis revealed that number of fruit per plant and average fruit weight had strong influence on fruit yield and the main determiners of fruit yield per plant. Therefore, improvement in yield can be achieved by selecting the genotypes which have more number of fruit per plant with more fruit weight.

\section{References}

Al-Jibouri HA, Miller PA and Robinson HF 1958. Genotypic and environmental variances and covariances in an upland cotton cross of inter specific origin. Agron. J. 50: 633-636.

Arnon D 1949. Copper enzymes in isolated chloroplasts. Polyphenoloxidase in Beta vulgaris. Plant Phys. 24(1): 1-15

Asati BS and Yadav DS 2004. Diversity of horticultural crops in north eastern region. ENVIS Bull. Himalayan Eco. 12:1-11.

Balasubramaniam T, Raj D, Kasthuri R and Rengaswami P 1982. Capsaicin and plant characters in chillies. Indian J. Hort. 39(3-4): 239-242.

Burton GW and EH de Vane 1953. Estimating heritability in tall fiscue (Festuca arundinacea) from replicated clonal materials. Agron. J. 45: 478-481.

Chattopadhyay A, Sharangi AB, Dai N and Dutta S 2011. Diversity of genetic resources and genetic association analyses of green and dry chillies of Eastern India. Chilean J. Agril. Res. 71(3): 350-356. 
Datta S and Jana JC 2010. Genetic variability, heritability and correlation in chilli genotypes under Terai zone of West Bengal. SAARC J. Agric. 8(1): 33-45.

Dewey JR and Lu KH 1959. A correlation and path analysis of components of crested wheat grass seed production. J. Agro. 51: 515-518.

Greenleaf WH 1986. Paper Breeding. In: Breeding vegetables crop. Baset MJ (ed). The Avi Publishing C., USA. pp. 68.

Jagota SK and Dani HM 1982. A new colorimetric technique for estimation of vitamin C using folin-phenol reagent. Annals of Bioch. 27 (1): 178-182.

Johnson HW, Robinson HF and Comstock RE 1955. Estimate of genetic and environmental variability in soybean. J. Agro. 47: 314-23.

Mathew D, Doijode SD and Reddy KM 2004. Correlation and path coefficient analysis in five species of capsicum. Capsicum and Eggplant Newsletter 23: 57-60.

Singh RK and Chaudhary BD 1985. Biometrical methods in quantitative genetic analysis. Kalyani Publisher, New Delhi. pp. 318.

Smitha RP and Basavaraj N 2006. Variability and correlation studies in chilli (C. annuum L.). Karnataka J. of Agric. Sci. 19(4): 888-891.

Witham FH, Blaydes BF and Devlin RM 1971. Experiments in plant physiology. Van Nostrand Reinhold, New York, USA. pp. 167-200.

(Manuscript received on 9 March, 2013; revised on 30 June, 2014) 